\title{
Application of Variable Zero-Moment Point in Walking Control of the Biped Robot
}

(Penggunaan Pemboleh Ubah Titik Momen Sifar pada Kawalan Berjalan Robot Dua Kaki)

\author{
CHENGLIN JiNG*
}

\section{ABSTRACT}

Using the predictive control based on zero-moment point (ZMP), the biped robot can walk comparatively stably. However, the problems such as lack of self-adaptivity are also highlighted mainly on account of modeling errors and environmental perturbations; specifically, the tracking errors of ZMP are generated, leading to a reduced walking stability. To address this problem, in the present work, the expected ZMP was decomposed into the reference ZMP which is pre-planned offline, and the variable ZMP which can be varied in real time. With the addition of the variable ZMP, the outside interferences can be eliminated. By combining the predictive control system and the inverse system of variable ZMP, the walking pattern of the robot with favorable self-adaptivity can be achieved. Finally, the simulation results indicate that the self-adaptivity of the robot can be effectively improved using the proposed control system.

Keywords: Biped robot; inverse system; predictive control; self-adaptivity; variable zero-moment point (ZMP)

\section{ABSTRAK}

Penggunaan kawalan ramalan berdasarkan titik momen sifar (ZMP), robot dua kaki boleh berjalan dengan agak stabil. Walau bagaimanapun, masalah seperti kekurangan penyesuaian diri juga diketengahkan terutamanya pada kesilapan pemodelan dan alam sekitar; secara khusus, kesilapan pengesanan ZMP dijana, membawa kepada pengurangan kestabilan berjalan. Untuk menangani masalah ini dalam kajian semasa, ZMP yang dijangka telah reput ke dalam rujukan ZMP yang dipra-rancang secara luar talian, dan pemboleh ubah ZMP yang boleh diubah dalam masa nyata. Dengan penambahan pemboleh ubah ZMP, gangguan luar boleh dihapuskan. Dengan menggabungkan sistem kawalan ramalan dan sistem songsang pemboleh ubah ZMP, pola berjalan robot dengan penyesuaian diri yang menggalakkan boleh dicapai. Kesimpulannya, keputusan simulasi menunjukkan bahawa penyesuaian diri robot boleh diperbaiki dengan berkesan menggunakan sistem kawalan cadangan.

Kata kunci: Kawalan ramalan; pemboleh ubah titik momen sifar (ZMP); penyesuaian diri; robot dua kaki; sistem songsang

\section{INTRODUCTION}

Walking control mainly focuses on the controlling of walking stability and self-adaptivity (Chang \& Liu 2012; Fu et al. 2013; Kljuno \& Williams 2010; Xue \& Chen 2012). Currently, the predictive control based on zero-moment point (ZMP) is one of the most advanced methods in walking control of the biped robot (Kajita et al. 2003; Zeng \& Yang 2014). According to the principle that the road conditions are necessary when walking, this ZMP-based predictive controller is designed using the target ZMP while the tracking of the target ZMP by the present ZMP can be achieved. Owing to the fact that the predictive control follows the idea of human brain's controlling on walking, it has been successfully applied in the advanced robot ASMIO (New ASIMO 2011; Yu et al 2009). As discussed by Kajita et al. (2003), the researchers from Japan firstly introduced the predictive control method in walking control of biped robot, and as discussed elsewhere (Khusainov et al. 2016; Kunimatsu et al. 2008; Park \& Youm 2007; Shimmyo et al. 2013). Some exploratory investigations have also been carried out by the authors in the present work, and the ranges of parameter values of the predictive controller were studied (Jing et al. 2010).

With the adoption of this ZMP-based predictive control method, although the comparatively stable walking of a biped robot is achieved, some problems still exist, in which lack of self-adaptivity is most prominent. The primary cause lies in the tracking errors of target ZMP during the walking of biped robot, mainly induced by modeling error and environmental perturbations (Czarnetzki et al. 2009; Huy et al. 2013; Jimmy 2010; Kajita et al. 2006; Sugihara \& Yamamoto 2017). Therefore, the walking stability is significantly reduced. To address these problems, the major research contents in the present work include: Due to the fact that the pre-defined expected ZMP is lack of self-adaptivity and meanwhile the environmental complexity is not taken into account during the walking process of robot, the expected ZMP is decomposed into the reference ZMP which is planned offline and the variable ZMP which is varied in real time (Gao \& Wang 2017; Hans et al. 2018; Liu et al. 2018; Mansour \& Shattuck 2017; Peng et al. 2017; Promsakon 2018). On account of the addition of real-time variable ZMP, the control can be free 
of outside interference and adaptive to the rugged ground, and moreover, the attitude control is also included. By combining the predictive control system and variableZMP-based inverse system, the walking pattern with selfadaptivity can be accomplished. The simulation results indicate that the self-adaptivity of a biped robot can be effectively improved using the proposed control method.

\section{METHODS}

\section{EFFECTS OF THE VARIABLE ZMP}

For a biped robot, the gait tracking errors are generally induced by environmental perturbations and mode mismatching during walking. As described in Jing et al. (2010), some stochastic disturbances could be eliminated to a certain degree by adjusting the parameters of the predictive controller; however, these tracking errors can hardly be eliminated in this way. To reduce or eliminate the tracking errors, the real-time variations of ZMP should be taken into account and adopted as the input of the predictive controller, rather than the offline pre-planned ZMP. In other words, the walking pattern can be self-adaptive only when the variable ZMP which can be varied in real time is added. With the environmental variations taken into account, the expected ZMP can be rewritten as:

$$
p^{\exp }=p^{\text {ref }}+p^{\text {var }}+\varepsilon
$$

where $p^{\text {exp }}$ denotes the expected ZMP; $p^{\text {ref }}$ denotes the reference ZMP; $p^{\text {var }}$ denotes the real-time variable ZMP; and $\varepsilon$ denotes the stochastic disturbances. The first item on the right side of (1), $p^{\text {ref }}$ is offline pre-planned according to the parameters such as walking speed, stride and gait cycle, and remains invariable during walking; i.e., the global stability of the robot is controlled by $p^{\text {ref }}$. The second item on the right side, $p^{\text {var }}$, which is added on account of environmental variations, can be used for controlling the local stability of the robot. The third item, $\varepsilon$ can be eliminated by adjusting the parameters of the predictive controller as described in Ref. (Jing et al. 2010). With the adoption of the variable ZMP $\left(p^{\text {var}}\right)$, the problems such as outside interferences, rugged ground and attitude control can be settled (Kajita et al. 2006). Apparently, only when $p^{\mathrm{var}}$ is taken into account, the walking model of a robot can be self-adaptive and similar to the characteristics of human walking that the gaits can be adjusted in real time. The effects of variable ZMP are elaborated as follows:

Elimination of external force As shown in Figure 1(a), when subjected to the impact of external forces, the resultant force on the robot is equivalent to the forward horizontal force $F$. To eliminate the interferences from external forces, the offline pre-planned reference ZMP should be moved towards the left. This left shift is achieved by adding the variable ZMP; i.e., the variable ZMP can be planned in real time according to the practical environmental variations. Aiming at ensuring that the robot is stable and undisturbed by the external forces, the moment of force generated by gravity relative to the variable ZMP should be balanced with the moment of external force, and accordingly the following expressions can be obtained:

$$
p^{\mathrm{var}}=-\frac{F z_{c}}{M g}
$$

where $z_{c}$ denotes the height of center of mass; $M$ is the mass of the robot; and $g$ denotes the gravitational acceleration.

As shown in (2), by planning the variable ZMP in real time on the basis of the offline pre-planned reference ZMP, the interferences of external forces can be effectively eliminated. Nevertheless, when the applied external force is too large, the ZMP moves to the heel and then the robot will rotate around the heel and even fall down. This suggests that the effects of eliminating external forces are limited to a certain degree.

Self-adaptivity to rugged ground As shown in Figure $1(\mathrm{~b})$, when the robot is walking on the rugged ground, the standing leg will be out of contact with the ground partly, and therefore, the tracing points of pre-planned ZMP may not locate in the supporting scope. At this moment, the variable ZMP is added by the walking pattern generator, so that the reference ZMP can be moved into the supporting scope where the heel is touched with ground and the robot can walk stably.
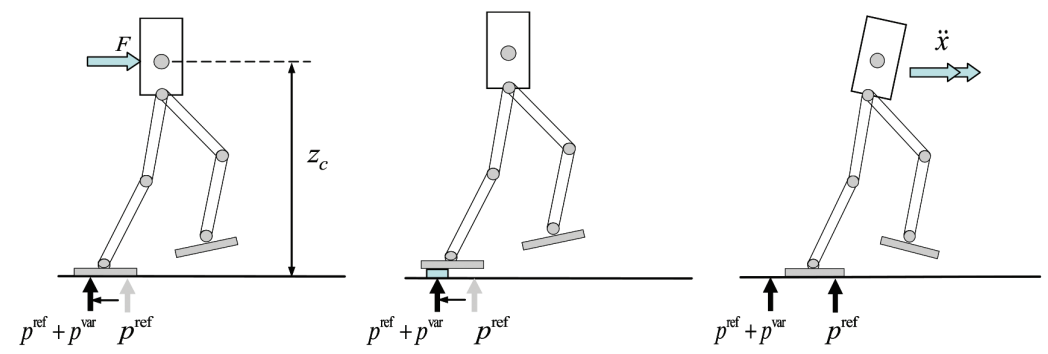

(a) Elimination of external force

(b) Self-adaptivity to rugged ground (c) Attitude control

FIGURE 1. Effects of variable ZMP 
Attitude control As displayed in Figure 1(c), when the upper body of the robot inclines forward due to environmental impacts, the balance can be restored by controlling the model ZMP. To be specific, when the upper body of the actual robot inclines forward compared with the upper body of the model, the upper body of the body is accelerated strongly, leading to the increase of target inertia and the rearward movement of the target ZMP relative to the original reference ZMP. Accordingly, the attitude of the actual robot is restored. The control method using the model ZMP has been widely applied in the biped robots produced by Honda (Kajita \& Guan 2007). In the present work, we speculate that the shift of ZMP can be achieved by adding the variable ZMP in walking pattern generator.

\section{ORIGIN OF THE INVERSE SYSTEM}

As shown in Figure 2, the biped robot can be approximated as a three-dimensional linear inverted pendulum (Kajita $\&$ Guan 2007). We suppose that the mass of the robot is focused on one point (also refers to as the mass point), and this linear inverted pendulum is composed of the massless legs which connect the mass point and the standing feet. Just like a person walks, the mass point is adjusted in a horizontal plane, while the heights of the plane relative to the center of the lines connecting two feet are fixed. Therefore, we can assume that the center of mass (CoM) of the robot along the direction of z-axis is a constant, by which on the one side, the amount of calculations decreases; on the other hand, a constant relative height of the mass point can contribute to the reduction of energy consumption. According to the stability principle during walking, only when the horizontal component of the moment of the reaction force from the ground is set as zero, the robot is stable. This action point with the moment of zero refers to as the zero-moment point (ZMP), which should always locate in the supporting polygon.
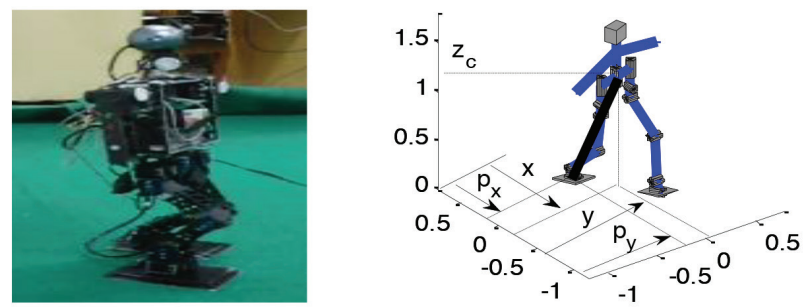

FIGURE 2. Model of the biped robot

Accordingly, at the ZMP as shown in Figure 2, the following expressions are satisfied,

$$
\begin{aligned}
& \tau_{x}=m g\left(x-p_{x}\right)-m \ddot{x} z_{c}=0 \\
& \tau_{y}=m g\left(y-p_{y}\right)-m \ddot{y} z_{c}=0
\end{aligned}
$$

After summarizing, the dynamic model can be written

$$
\ddot{x}=\frac{g}{z_{c}}\left(x-p_{x}\right), \ddot{y}=\frac{g}{z_{c}}\left(y-p_{y}\right)
$$

where $x$ and $y$ denote the displacements of the mass point $(\mathrm{CoM})$ in the horizontal plane; $z_{c}$ denotes the height of the mass point $(\mathrm{CoM}) ; g$ is the gravitational acceleration; while $p_{x}$; and $p_{y}$ denote the positions of ZMP in the horizontal plane. In the following paragraphs, we will focus on the movements of the robot along the direction of $\mathrm{x}$-axis and conduct further analyses and demonstrations, while this analytical method is also applicable for the movements along the direction of $y$-axis.

The dynamic system of a robot can be regarded as a servo system, and thus the first expression in (4) can be rewritten in a state-space from. The differential of ZMP with respect to time is defined as the input variable of the system, i.e., $v=\dot{p}_{x}=\dot{p}$, while the ZMP along the direction of $\mathrm{x}$-axis is defined as the output. Accordingly, the state-space expressions of the servo system can be written as:

$$
\begin{aligned}
& \frac{\mathrm{d}}{\mathrm{d} t}\left[\begin{array}{l}
x \\
\dot{x} \\
p
\end{array}\right]=\left[\begin{array}{ccc}
0 & 1 & 0 \\
\frac{g}{z_{c}} & 0 & -\frac{g}{z_{c}} \\
0 & 0 & 0
\end{array}\right]\left[\begin{array}{l}
x \\
\dot{x} \\
p
\end{array}\right]+\left[\begin{array}{l}
0 \\
0 \\
1
\end{array}\right] v \\
& p=\left[\begin{array}{lll}
0 & 0 & 1
\end{array}\right]\left[\begin{array}{l}
x \\
\dot{x} \\
p
\end{array}\right]
\end{aligned}
$$

The continuous state-space expressions, as shown in (5) were then discretized with the sampling time of $\Delta t$ :

$$
\begin{aligned}
& x_{k+1}=A_{1} x_{k}+B_{1} v_{k} \\
& p_{k}=C_{1} x_{k}
\end{aligned}
$$

where, $\boldsymbol{x}_{k}=\left[\begin{array}{lll}x(k \Delta t) & \dot{x}(k \Delta t) & p(k \Delta t)\end{array}\right]^{\mathrm{T}}, v_{k}=v(k \Delta t)$ and $p_{k}=p(k \Delta t)$.

To produce a stable walking, the output $p_{k}$ of the dynamic system of the biped robot should trace the target $Z M P, p_{k}^{\text {ref }}$, as precisely as possible, and the walking pattern is generated on line using predictive control. The following tracking performance index should be minimized by the predictive controller (Katayama et al. 1985):

$$
J=\sum_{j=1}^{\infty}\left\{q\left(p_{j}^{\text {ref }}-p_{j}\right)^{2}+r u_{j}^{2}\right\}
$$

where $q$ and $r$ denote the positive weighting coefficients. This index means that the tracking errors should remain approximately zero with lesser control energy. According to the theory of predictive control (Katayama et al. 1985), this minimization of the performance index can be achieved by minimizing the target reference values of the next $\mathrm{N}$ steps with the use of ZMP. The designed predictive controller can be expressed as: as: 
$v_{k}=-\boldsymbol{K} \boldsymbol{x}_{k}+\left[f_{1}, f_{2}, \cdots, f_{N}\right]\left[\begin{array}{c}p_{k+1}^{\mathrm{ref}} \\ \vdots \\ p_{k+N}^{\mathrm{ref}}\end{array}\right]$.

where $K$ and $f_{j}$ follow the expressions as follow:

$$
\begin{aligned}
& \boldsymbol{K}=\left(r+\boldsymbol{B}_{1}^{\mathrm{T}} \boldsymbol{P} \boldsymbol{B}_{1}\right)^{-1} \boldsymbol{B}_{1}^{\mathrm{T}} \boldsymbol{P} \boldsymbol{A}_{1} \\
& \left.f_{j}=\left(r+\boldsymbol{B}_{1}^{\mathrm{T}} \boldsymbol{P} \boldsymbol{B}_{1}\right)^{-1} \boldsymbol{B}_{1}^{\mathrm{T}}\left[\boldsymbol{A}_{1}-\boldsymbol{B}_{1} \boldsymbol{K}\right)^{\mathrm{T}}\right]^{-1} \boldsymbol{C}_{1}^{\mathrm{T}} \boldsymbol{q} \\
& (j=1,2, \mathrm{~L}, N)
\end{aligned}
$$

The matrix $\mathrm{P}$ is the solution of the following discrete Riccati equation:

$$
\boldsymbol{P}=\boldsymbol{A}_{1}^{\mathrm{T}} \boldsymbol{P} \boldsymbol{A}_{1}+\boldsymbol{C}_{1}^{\mathrm{T}} q \mathbf{C}_{1}-\boldsymbol{A}_{1}^{\mathrm{T}} \boldsymbol{P} \boldsymbol{B}_{1}\left(r+\boldsymbol{B}_{1}^{\mathrm{T}} \boldsymbol{P} \boldsymbol{B}_{1}\right)^{-1} \boldsymbol{B}_{1}^{\mathrm{T}} \boldsymbol{P} \boldsymbol{A}_{1}
$$

To substitute (8) into (6), we also define $\boldsymbol{A}=\boldsymbol{A}_{1}-\boldsymbol{B}_{1} \boldsymbol{K}$, $\boldsymbol{B}=\boldsymbol{B}_{1}$ and $\boldsymbol{C}=\boldsymbol{C}_{1}$, and then the original system expressions as described in (6) can be changed into:

$$
\begin{aligned}
& \boldsymbol{x}_{k+1}=\boldsymbol{A} \boldsymbol{x}_{k}+\boldsymbol{B} u_{k} \\
& p_{k}=\boldsymbol{C} \boldsymbol{x}_{k}
\end{aligned}
$$

The input of control can be expressed as:

$$
u_{k}=\sum_{j=1}^{N} f_{j} p_{k+j}^{\text {ref }}
$$

Then the pulse transfer function as described in (11) can be written as:

$$
G(z)=\boldsymbol{C}(z \boldsymbol{I}-\boldsymbol{A})^{-1} \boldsymbol{B}
$$

Aiming at adding the variable ZMP in real time according to the environmental variations, the variable ZMP subsystem should be designed. Define a variable ZMP subsystem $G^{\text {inv }}(z)$ which also satisfies the following expressions,

$$
G(z) \cdot G^{\text {inv }}(z)=z^{-1}
$$

This variable ZMP subsystem can be regarded as an inverse system of the original predictive control system, which is just the origin of the inverse system.

\section{DESIGN OF THE INVERSE SYSTEM}

As shown in Figure 3, with the purpose of constructing a predictive control system with variable ZMP, an inverse system is constructed. The buffer in Figure 3 serves as storage for the reference values of target ZMP, while the input can be taken as the current reference. For the whole system, the reference value of ZMP in buffer and the variable ZMP are used for the input of control. The variable ZMP system is achieved by inversing the predictive control system as described in (11), and the construction of the state-space model of this inverse system is as illustrated.

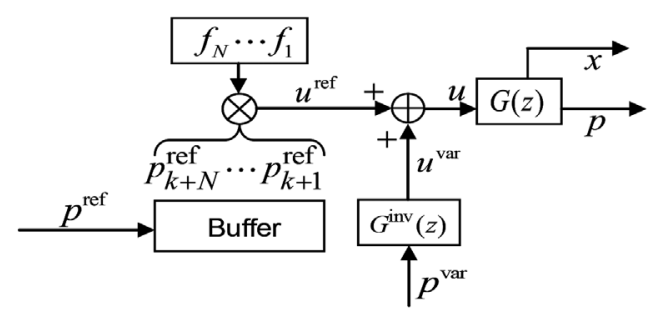

FIGURE 3. The predictive control system with variable ZMP

By performing the forward translation on (11b) for a sampling instant and we can obtain the following expression:

$$
p_{k+1}=\boldsymbol{C} \boldsymbol{x}_{k+1}=\boldsymbol{C} \boldsymbol{A} \boldsymbol{x}_{k}+\boldsymbol{C B} u_{k}
$$

Since $\boldsymbol{C} \boldsymbol{B} \neq 0$, we can deduce that:

$$
u_{k}=-(\boldsymbol{C B})^{-1} \boldsymbol{C A} \boldsymbol{x}_{k}+(\boldsymbol{C B})^{-1} p_{k+1}=\boldsymbol{C}_{2} \boldsymbol{x}_{k}+\boldsymbol{D}_{2} p_{k+1}
$$

where $\boldsymbol{C}_{2}=-(\boldsymbol{C B})^{-1} \boldsymbol{C A}$ and $\boldsymbol{D}_{2}=(\boldsymbol{C B})^{-1}$

As concluded from (11a) and (16), the following state equation can be obtained:

$$
\boldsymbol{x}_{k+1}=\left(\boldsymbol{A}+\boldsymbol{B} \boldsymbol{C}_{2}\right) \boldsymbol{x}_{k}+\boldsymbol{B} \boldsymbol{D}_{2} p_{k+1}
$$

Set $\boldsymbol{A}_{2}=\boldsymbol{A}+\boldsymbol{B} \boldsymbol{C}_{2}$ and $\boldsymbol{B}_{2}=\boldsymbol{B} \boldsymbol{D}_{2}$, the state-space model of the variable ZMP subsystem can be derived by (16) and (17):

$$
\begin{aligned}
& \boldsymbol{x}_{k+1}^{\mathrm{inv}}=\boldsymbol{A}_{2} \boldsymbol{x}_{k}^{\mathrm{inv}}+\boldsymbol{B}_{2} p_{k}^{\mathrm{var}} \\
& u_{k}^{\mathrm{var}}=\boldsymbol{C}_{2} \boldsymbol{x}_{k}^{\mathrm{inv}}+\boldsymbol{D}_{2} p_{k}^{\mathrm{var}}
\end{aligned}
$$

where $\boldsymbol{x}_{k}^{\text {inv }}$ denotes the state variable of this variable inverse system, and therefore, the pulse transfer function of the inverse system can be expressed as:

$$
G^{\text {inv }}=\boldsymbol{C}_{2}\left(z \boldsymbol{I}-\boldsymbol{A}_{2}\right)^{-1} \boldsymbol{B}_{2}+\boldsymbol{D}_{2}
$$

As stated, the inverse system is constructed based on the original predictive control system as described in (11), with the structure diagram displayed in Figure 3. 


\section{RESULTS AND DISCUSSION}

\section{NUMERICAL VERIFICATION}

According to the arguments about the parameters of the predictive controller in Jing et al. (2010), several control parameters $r, q$ and the predictive step length $N$ were selected and listed in Table 1.

Referring to Jing et al. (2010), the value of $k$ is $-15 \leq$ $k \leq-3$, where numerical verification is performed by $k=$ -6 . Using these parameters, based on the pulse transfer function (13) of the predictive control system as described in Origin of the inverse system section, the pulse transfer function can be calculated as:

$$
G(z)=\boldsymbol{C}(z \boldsymbol{I}-\boldsymbol{A})^{-1} \boldsymbol{B}=\frac{0.005(z-1.017)(z-0.9832)}{(z-0.9832)^{2}(z-0.03709)}
$$

Similarly, based on the pulse transfer function (19) of the inverse system as described in Design of the Inverse Systems Section, the pulse transfer function can be calculated as:

$$
\begin{aligned}
G^{\text {inv }}(z) & =\boldsymbol{C}_{2}\left(z \boldsymbol{I}-\boldsymbol{A}_{2}\right)^{-1} \boldsymbol{B}_{2}+\boldsymbol{D}_{2} \\
& =\frac{(z-0.9832)^{2}(z-0.03709)}{0.005 z(z-1.017)(z-0.9832)}
\end{aligned}
$$

Obviously, $G(z) \cdot G^{\text {inv }}(z)=z^{-1}$, i.e., the designed inverse system can satisfy the definition of inverse system.

\section{SIMULATION ANALYSIS}

From the transfer function of the inverse system as shown in (21), we can observe that the extremes are not completely located in the unit circle. According to the extreme principle of the pulse transfer function in a discrete system, the inverse system is not stable and the extreme assignment should be performed. Based on the controllability theory of the linear system, the inverse system described by the state-space model in (18) is absolutely controllable, and the extremes can be assigned randomly by state feedback. Figure 4 displays the new constructed inverse system.

Since the inverse system described in (18) is absolutely controllable, the extremes of the inverse system can be randomly assigned according to the theory of extreme assignment. The inverse system can be stable only when the assigned extremes locate in the unit circle. However, the transmission matrix of the system as describe in (18) does not equal to zero, i.e., $\boldsymbol{D}_{2} \neq 0$, this system is not a strictly authentic system, and the assignment of extremes can affect the zero point of the inverse system. With a certain stability margin taken into account, the extremes were assigned to be $0.3,0.4$ and 0.5 , respectively. After calculation, the feedback matrix of the inverse system can be described as:

$$
\boldsymbol{K}^{\text {inv }}=\left[\begin{array}{lll}
-729.8890 & -14.9230 & 0.3351
\end{array}\right]
$$

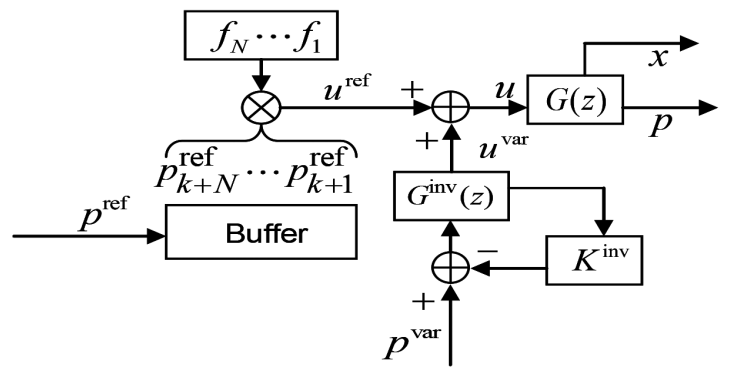

FIGURE 4. Predictive control system with a stable inverse system

Accordingly, the pulse transfer function of the inverse system can be converted into the following expression:

$$
\begin{aligned}
G^{\text {inv }}(z) & =\boldsymbol{C}_{2}\left(z \boldsymbol{I}-\boldsymbol{A}_{2}+\boldsymbol{B}_{2} \boldsymbol{K}^{\text {inv }}\right)^{-1} \boldsymbol{B}_{2}+\boldsymbol{D}_{2} \\
& =\frac{(z-0.642)\left(z^{2}-0.5611 z+0.1493\right)}{0.005(z-0.5)(z-0.4)(z-0.3)}
\end{aligned}
$$

Although the null point was changed, it still located in the unit circle; i.e. the comparatively complete predictive control system with a stable inverse system was constructed. In the following sections, the performances of the constructed predictive control system will be verified.

According to the discussions in Effects of the Variable section, the variable ZMP plays important roles in adjusting and stabling the robot during walking. The global stability of the robot is controlled by the reference ZMP, whose parameters such as stride length, walking speed and walking cycle, which cannot be easily changed during walking. When the robot is subjected to the interference such as external fore, rugged ground and gait imbalance, the variable ZMP should be added to perform adjustable control. In line with the environmental variations of the robot, the variable ZMP is diverse. In the present work, the sinusoid curves $p^{\mathrm{var}}=0.05 \sin (50 t)$ and $p^{\mathrm{var}}=0.08 \sin (50 t)$ were selected as the variable ZMP. Figure 4 of the predictive control system with inverse system is verified. The result is shown in Figure 5. When the parameter of the predictive controller is $k=-3$, it shows that the variable ZMP cannot

TABLE 1. Structure parameters and the related parameters of the predictive controller

\begin{tabular}{cccccc}
\hline $\begin{array}{c}\text { Gravitational } \\
\text { acceleration }(\mathrm{g})\end{array}$ & $\begin{array}{c}\text { Height of } \\
\mathrm{CoM}\left(\mathrm{z}_{\mathrm{c}}\right)\end{array}$ & $\begin{array}{c}\text { Sampling } \\
\text { time }(\Delta t)\end{array}$ & $\begin{array}{c}\text { weighting } \\
\text { coefficients }(q)\end{array}$ & $\begin{array}{c}\text { weighting } \\
\text { coefficients }(r)\end{array}$ & $\begin{array}{c}\text { Predictive } \\
\text { step }(N)\end{array}$ \\
\hline $9.8\left[\mathrm{~m} / \mathrm{s}^{2}\right]$ & $0.85[\mathrm{~m}]$ & $0.005[\mathrm{~s}]$ & 1 & $1 \times 10^{-k}$ & 320 \\
\hline
\end{tabular}




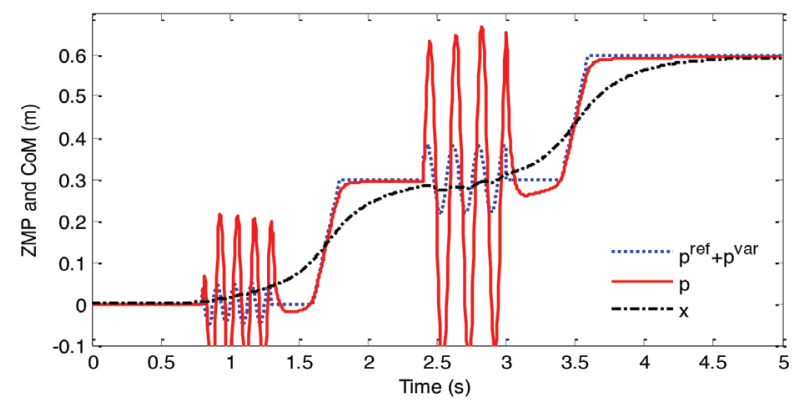

FIGURE 5. Tracking performances on the variable ZMP of the predictive control system with inverse system

be tracked well. When the parameters are $k=-6$ or -15 $\leq k \leq-6$, the accurate tracking of the variable ZMP can be achieved. This shows that the predictive control system with inverse system can track variable ZMP well when the controller parameters are good. The results confirm the conclusions as predicted in the introduction, i.e. the self-adaptivity of the biped robot can be greatly improved during walking.

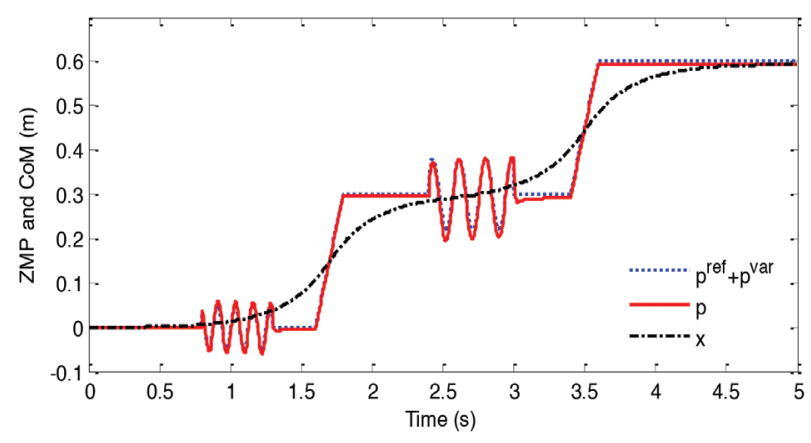

FIGURE 6. Tracking performances on the variable ZMP of the predictive control system with a stable inverse system
The prototype of biped robot is used to verify the tracking of variable ZMP by predictive control system with inverse system when the parameters of the controller are good. The trajectory curves of ZMP and CoM are detected and the torso position sensor is used to detect the position of CoM, and the position sensor here adopts encoder. The force sensor is used to obtain the contact condition between the biped robot and the ground. The ZMP, in the walking process of the computer can convert the ZMP measurement into the center of pressure $(\mathrm{CoP})$ measurement because the ZMP of the robot coincides with the CoP of the ground reaction force during the walking process. The force sensing device adopts thin film soles sensor, which is used to measure the ground reaction force. Each soles are equipped with 4 pieces, which are distributed at four points of the soles of the feet. The detection and calculation formula of the actual ZMP is as follows:

$$
p_{x}=\frac{\sum_{i=1}^{N} p_{i x} f_{i z}}{\sum_{i=1}^{N} f_{i z}}, \quad p_{y}=\frac{\sum_{i=1}^{N} p_{i y} f_{i z}}{\sum_{i=1}^{N} f_{i z}}
$$

where, $p_{x} \times p_{y}$ the position of the ZMP in the horizontal plane, $\left(p_{i x^{\prime}} p_{i y^{\prime}} p_{i z}\right)$ represents the spatial coordinates of the $i$ sensor, $f_{i z}$ the vertical force from the ground perceived by the $i$ sensor. One-legged support period $N=4$, bipedal support period $N=8$.

Based on the design and research, the walking experiment is completed on the prototype, and the CoM and ZMP trajectory data are detected. Table 2 is the CoM coordinate data of 20 sample points. Table 3 is the ZMP coordinate data for 20 sample points. Figure 7 shows the trajectory curves of ZMP and CoM drawn according to the detected coordinate data during motion. It can be seen from the diagram that the actual ZMP trajectory basically

TABLE 2. CoM detection data sample point

\begin{tabular}{ccccccccccc}
\hline $\mathrm{t}$ & 0.3 & 0.6 & 0.9 & 1.2 & 1.5 & 1.8 & 2.1 & 2.4 & 2.7 & 3 \\
\hline $\mathrm{x}$ & 0.0001 & 0.0568 & 0.0938 & 0.1468 & 0.1749 & 0.1915 & 0.2635 & 0.2957 & 0.3289 & 0.4026 \\
$\mathrm{y}$ & -0.0749 & -0.0285 & 0.0421 & 0.0713 & 0.0716 & 0.0721 & -0.0669 & -0.0756 & -0.0826 & 0.0517 \\
$\mathrm{t}$ & 3.3 & 3.6 & 3.9 & 4.2 & 4.5 & 4.8 & 5.1 & 5.4 & 5.7 & 6 \\
$\mathrm{x}$ & 0.5215 & 0.5738 & 0.6021 & 0.6439 & 0.7429 & 0.8389 & 0.8745 & 0.8868 & 0.8906 & 0.8921 \\
$\mathrm{y}$ & 0.0021 & -0.0774 & -0.0903 & -0.0887 & 0.0745 & -0.0137 & -0.0736 & -0.0859 & -0.0864 & -0.0834 \\
\hline
\end{tabular}

TABLE 3. ZMP detection data sample point

\begin{tabular}{ccccccccccc}
\hline $\mathrm{t}$ & 0.3 & 0.6 & 0.9 & 1.2 & 1.5 & 1.8 & 2.1 & 2.4 & 2.7 & 3 \\
\hline $\mathrm{P}_{\mathrm{x}}$ & -0.0012 & 0.0576 & 0.1208 & 0.2021 & 0.2235 & 0.2964 & 0.3245 & 0.3949 & 0.4246 & 0.4939 \\
$\mathrm{P}_{\mathrm{y}}$ & -0.0737 & -0.0105 & 0.0609 & 0.0613 & -0.0102 & -0.0748 & -0.0763 & 0.0369 & 0.0615 & 0.0633 \\
$\mathrm{t}$ & 3.3 & 3.6 & 3.9 & 4.2 & 4.5 & 4.8 & 5.1 & 5.4 & 5.7 & 6 \\
$\mathrm{P}_{\mathrm{x}}$ & 0.5226 & 0.5746 & 0.6538 & 0.6931 & 0.7204 & 0.7545 & 0.7936 & 0.8227 & 0.8526 & 0.8927 \\
$\mathrm{P}_{\mathrm{y}}$ & 0.0464 & -0.0718 & -0.0608 & 0.0037 & 0.0308 & 0.0738 & 0.0626 & 0.0117 & -0.0416 & -0.0829 \\
\hline
\end{tabular}




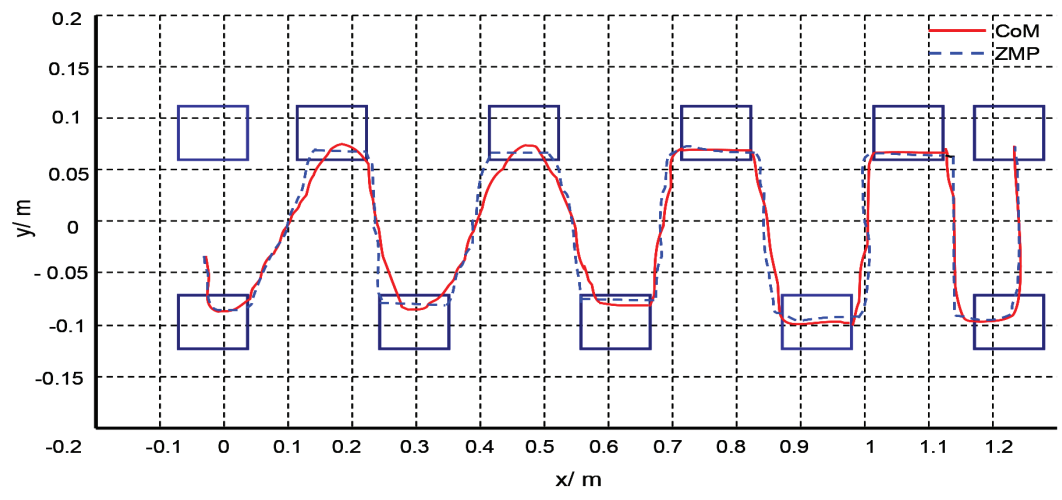

FIGURE 7. ZMP and CoM chart during walking

falls in the support domain, and the robot can walk stably. It is further shown that the predictive control system with inverse system can track the variable ZMP, when the parameters of the controller are good. This confirms the results mentioned in the introduction, and the method in this paper can improve the adaptability of biped robot walking.

\section{CONCLUSION}

The self-adaptivity of the biped robot during walking using the ZMP-based control method was investigated in the present work. Generally, for the convenience of design, the offline pre-planned ZMP was adopted as the input of predictive controller, while the environmental complexity during walking was not taken into account, leading to a significantly reduced walking stability. In the present work, by decomposing the expected ZMP into the off-line pre-planned reference ZMP and the real-time variable ZMP, the predictive control system with stable inverse system was constructed, and accordingly, the self-adaptivity of the biped robot using the ZMP-based control method could be improved. Moreover, the feasibility of the proposed method was verified by the simulations. The study in the present work can provide solid theoretical bases for the stable walking of the robot in practical applications. In the further work, the proposed method will be applied in actual robots.

\section{ACKNOWLEDGMENTS}

This research is financially supported by Science and technology plan of Guizhou Province of China ([2017]1017 and [2018]1024).

\section{REFERENCES}

Chang, J. \& Liu, G. 2012. Designing a control system for humanoid soccer robots. Computer Applications and Software 29(11): 302-304, 333.

Czarnetzki, S., Kerner, S. \& Urbann, O. 2009. Observer-based dynamic walking control for biped robots. Robotics and Autonomous Systems 57(2009): 839-845.

Fu, G., Yang, Y., Chen, J. \& Li, J. 2013. Walking control for humanoid robot based on ZMP error correction. Robot 35(1): 39-44.
Gao, W. \& Wang, W.F. 2017. The fifth geometric-arithmetic index of bridge graph and carbon nanocones. Journal of Difference Equations and Applications 23(1-2SI): 100-109.

Hans, S., Tripathi, D., Mogbademu, A.A. \& Tyagi, B. 2018. Inequalities for rational functions with prescribed poles. Journal of Interdisciplinary Mathematics 21(1): 157-169.

Huy, T.D., Phuong, N.T., Loc, H.D. \& Cuong, N.C. 2013. A simple walking control method for biped robot with stable gait. Journal of Computer Science and Cybernetics 29(2): 105-118.

Jimmy, O.R. 2010. A hybrid CPG-ZMP control system for stable walking of a simulated flexible spine humanoid robot. Neural Networks 23(1): 452-460.

Jing, C., Xue, F., Zhang, H. \& Li, Z. 2010. Implementation method of predictive control for biped robot stabilization walking pattern. Chinese Journal of Scientific Instrument 31(12): 2700-2705.

Kajita, S.\& Guan, Y. 2007. Humanoid Robots. Beijing: Tsinghua University Press.

Kajita, S., Morisawa, M., Harada, K., Kaneko, K., Kanehiro, F. \& Fujiwara, K. 2006. Biped walking pattern generator allowing auxiliary ZMP Control. Internationonal Conference on Intelligent Robots and Systems. Beijing, China. pp. 29932999.

Kajita, S., Kanehiro, F., Kaneko, K., Fujiwara, K., Harada, K., Yokoi, K. \& Hirukawa, H. 2003. Biped walking pattern generation by using preview control of zero-moment point. Conference on Robotics \& Automation. Taiwan, China. pp. 1620-1626.

Katayama, T., Ohki, T. \& Inoue, T. 1985. Design of an optimal controller for a discrete time system subject to previewable demand. International Journal of Control 41(3): 677-699.

Khusainov, R., Afanasyev, I., Sabirova, L. \& Magid, E. 2016. Bipedal robot locomotion modelling with virtual height inverted pendulum and preview control approaches in Simulink environment. Journal of Robotics, Networking and Artificial Life 3(3): 182-187.

Kljuno, E. \& Williams, R.L. 2010. Humanoid walking robot: Modeling, inverse dynamics, and gain scheduling control. Journal of Robotics 2010: Article ID: 278597.

Kunimatsu, S., Fukuda, T., Nakasaki, K. \& Ishitobi, M. 2008. $l_{\infty}$ Preview control for biped walking pattern generation. SICE Annual Conference. Japan: The University ElectroCommunications. pp. 1916-1919.

Liu, Z., Peng, W., Zare, Y., Hui, D. \& Rhee, K.Y. 2018. Predicting the electrical conductivity in polymer carbon nanotube nanocomposites based on the volume fractions 
and resistances of the nanoparticle, interphase, and tunneling regions in conductive networks. RSC Advances 8(34): 1900119010.

Mansour, T. \& Shattuck, M. 2017. Set partitions and parity successions. Journal of Discrete Mathematical Sciences and Cryptography 20(8): 1651-1674.

New ASIMO. 2011. Honda Motor Co. Ltd., New ASIMO [EB/ OL].http://world.honda.com/HDTV/ASIM-O/New-ASIMOrun- $6 \mathrm{kmh}$-slomo/index.htm

Park, J. \& Youm, Y. 2007. General ZMP preview control for bipedal walking. IEEE International Conference on Robotics and Automation. Roma, Italy. pp. 2682-2687.

Peng, W.X., Wang, L.S., Mirzaee, M., Ahmadi, H., Esfahani, M. \& JFremaux, S. 2017. Hydrogen and syngas production by catalytic biomass gasification. Energy Conversion and Management 135: 270-273.

Promsakon, C. 2018. Edge colorability of unitary endo-cayley graphs of cyclic groups. Journal of Discrete Mathematical Sciences and Cryptography 2(1): 191-198.

Shimmyo, S., Sato, T. \& Ohnishi, K. 2013. Biped walking pattern generation by using preview control based on three-mass model. IEEE Transactions on Industrial Electronics 60(11): 5137-5147.

Sugihara, T. \& Yamamoto, T. 2017. Foot-guided agile control of a biped robot through ZMP manipulation. IEEE International Conference on Intelligent Robots and Systems. Vancouver, Canada. pp. 4546-4551.
Xue, F. \& Chen, X. 2012. Novel gait pattern planning method for increasing flexibility of biped robot. Journal of Chinese Computer Systems 33(9): 1928-1933.

Yu, X., Wei, S. \& Liao, Q. 2009. Development and technology research of humanoid robot. Journal of Mechanical Engineering 45(3): 71-75.

Zeng, H. \& Yang, Y. 2014. On-line gait planning by using preview control of zero moment point. Journal of Computer Applications 34(2): 514-518.

School of Mathematics and Statistics

Guizhou University of Finance and Economics

Guiyang, 550025

China

*Corresponding author; email: 1265805946@qq.com

Received: 21 February 2019

Accepted: 23 December 2019 